\title{
Observing Problem-Solving Strategies in Disabled Children and Adolescents with the Use of Check-Lists
}

\author{
Elisabetta Sagone*, Maria Elvira De Caroli, Maria Luisa Indiana, Rossella Falanga, Erica \\ Napoli \\ Department of Educational Sciences, University of Catania
}

*Corresponding Author: Elisabetta Sagone, Department of Educational Sciences, University of Catania

\begin{abstract}
This paper debates the usage of check-lists to assess behavioral patterns linked to problem-solving strategies adopted by disabled children and adolescents during the execution of different tasks (Tower of Hanoi; Tetris Game; set of Building Blocks). Together with assessment grids, these tools are frequently used in the application of observational method to value behavioral patterns in typical and atypical growth, but rarely applied in the analysis of problem-solving strategies in disabled children and adolescents. For this reason, check-lists have been created to mark the presence or absence of solution behaviors. Check-lists valued both general behaviors connected with problem-space approach and specific behaviors linked to structured, semi-structured, and unstructured tasks. These tools can be used by independent judges to assess the same problem-solving strategies used by disabled individuals, adopting the Cohen's kappa coefficient or Fleiss index for inter-rates reliability. These check-lists can allow early childhood educators and others (teachers and parents) to better evaluate the quality of cognitive abilities expressed by atypically and typically developed children and adolescents; further, scholars can examine performances of disabled individuals comparing them to those of typically developed contemporaries. Future research will be addressed towards the implementation of problem-solving strategies in disabled children and adolescents through educational trainings with systematic observations.
\end{abstract}

Key words: check-list, problem-solving, disability, Tower of Hanoi, Tetris Game, set of Building Blocks

\section{INTRODUCTION}

Problem-solving is one of the most important components of executive functions, together with inhibitory control, working memory, sustain attention, cognitive flexibility, and planning. It is a process directly involved in the solution of problems with efficient strategies and described as a "cycle from recognizing the problem to creating a solution, evaluating the solution, and going back to recognizing a new problem encountered" [1]. In these terms, the "problem" is something that takes place when individuals pursue a goal but ignore how to achieve this goal because they are deeply blocked by an obstacle. Scholars examined the different components of problem-solving process in developmental age including specific cognitive and meta-cognitive skills $[2,3,4,5]$; in addition, researchers developed tasks to assess each component of executive functioning (including the problem-solving process) both in atypical and typical developed individuals, predominantly disabled children. For example, the Wisconsin Card Sorting Test [6], the Tower of London [7, 8], the Dimensional Change Card Sort [9], and the Tower of Hanoi [10] have been used to examine problemsolving, planning, flexibility, and abstract reasoning. To cite one of these tasks, in detail, the Tower of London [11] is chosen to assess problem-solving processing and planning and, similarly to the Tower of Hanoi, consists of a set of three balls differing in color that are moved one at a time from one peg to another. Each of the three pegs of descending lengths can hold only three, two, or one ball, respectively. The total move score corresponds to the number of moves beyond the minimum number of moves required to reach the goal position summed over all problems; the total correct score is given by the total number of solved problems in the minimum number of moves. These scores are used to assess the ability of planning and problem-solving. The aforementioned tasks produce scores about the efficiency or inefficiency of executive functioning in different populations adopting a quantitative approach and frequently comparing the performances obtained by disabled individuals with those of typically developed ones. 
Previous researchers found that students with Down syndrome (DS), Williams syndrome (WS), learning disabilities (LD), and other intellectual disabilities (ID) achieved lower scores in cognitive flexibility and meta-cognitive tasks than their mental age-matched peers with typical development using nonverbal and verbal tasks $[12,8,13,14,15]$. Literature reported that learning disabled students (LD) are deficient in selective attention (e.g, the ability to attend to relevant stimuli presented in a learning or problem-solving situation) and in arithmetic skills (e.g., syntax, mental and written calculation), self-regulatory and control functions [16, 17, 18, 19] and score lower than contemporaries in inferential and meta-cognition skills [20,21]. Zelazo and colleagues [22] reported that low-functioning students with DS have greater difficulty of shifting between conflicting events and concepts with false-belief tasks than mental age-matched peers. Lanfranchi, Cornoldi, and Vianello [23] studied performances of disabled students in verbal and visuo-spatial working memory, noticing that the degree of difficulty in verbal and visuo-spatial working memory for students with DS was higher when the required control was in high-condition. More recently, the study of Meneghetti, Toffalini, Carretti, and Lanfranchi [24] on mental rotation ability (measured through the Ghost Picture Test by Frick et al., [25]) and its relation to fluid intelligence and everyday spatial activities in a group of children with DS and a group of children with typical development revealed that the former is less accurate in mental rotation than the latter and mental rotation ability is related to fluid intelligence in both groups of children. With regard to cross-syndrome comparisons, Russell, Jarrold and Henry [26] found that children with Autism syndrome (AS) utilized the articulatory loop (one of the three components of working memory model proposed by Baddeley, [27]) in a similar way to typically developed children, showed superior memory span to peers with moderate learning disabilities, and are not specifically impaired on tasks measuring working memory capacity. Costanzo et al. [8] found that individuals with DS performed worse than those with WS in verbal shifting tasks. As found by Lanfranchi et al. [12], students with DS performed at a significantly lower level in tasks of set shifting, inhibition/perseveration, planning/problem-solving, and working memory, but not in the tasks of fluency; in addition, students with DS produced an high number of errors and used inefficient strategies for the sustained attention. Lastly, Lanfranchi, Jerman, and Vianello [28] analyzed the working memory and its relationships with other cognitive processes in students with DS compared to typically developed peers, revealing that students with DS expressed deficits in both central executive functioning and verbal components of working memory.

Concerning the type of problem-solving strategies used by disabled individuals in structured tasks $[12,29]$, scholars reported little empirical evidences and these strategies have been explored in this population in an indirect way. For this reason, the main goal of the current paper is to provide tools useful to observe and value problem-solving strategies of disabled children and adolescents through the observational method $[30,31]$ to overcome the exclusivity of quantitative approach in this field. No research present in the main databases has dealt with these analyses in atypical population in developmental age using this specific and systematic methodology probably because of the difficulty to identify the coding of observations with detailed behavioral check-lists. Pilot observations allowed us to collect a depth of information about problem-solving strategies (but not a breadth of data) and to reduce one of the most important limits of this type of research consisting of the interpretation by the observers.

\section{Methodology}

\subsection{Purposes of Qualitative Study}

The main purpose of this paper is to offer an example of check-lists to assess behavioral patterns linked to problem-solving strategies usable by disabled children and adolescents during the execution of differently structured tasks.

The secondary purpose is to suggest a project work based on the observation of behavioral patterns concerning the approach to problem-solving strategies comparing disabled children and adolescents to control groups.

\subsection{Participants}

Disabled children and adolescents with different levels of intellectual disability (preferably, mild and moderate disability) could be involved to answer to the first purpose. Further, two control groups, respectively, composed by mental-age matched children and adolescents with typical development (e.g. using Raven's Colored Matrices) or matched on performance about cognitive and meta-cognitive 
measures (e.g. cognitive tasks and false beliefs tasks), could be included to reply to the second purpose of the project work.

\subsection{Tasks}

To analyze problem-solving strategies the authors suggest to use the three following tasks or others of similar composition/typology: the Tower of Hanoi (ToH, structured task1), the Tetris Game (TG, semi-structured task2), and the Set of Building Blocks (SBB, unstructured task3). The Tower of Hanoi could be substituted by the Tower of London, the Tetris Game by different types of Puzzle game, and the set of Building Blocks by LEGO, DUPLO, or Tangrams for Kids.

\subsubsection{Tower of Hanoi $(\mathrm{ToH})$}

This task can be chosen to observe the abilities of planning and problem-solving and consists of four disks of successively decreasing diameter $(6 \mathrm{~cm}, 8 \mathrm{~cm}, 10 \mathrm{~cm}$, and $12 \mathrm{~cm})$ stacked on one of three vertical pegs; it requires to move the stack to another peg one disk at a time, never stacking a larger disk on a smaller one in the fewest possible moves. The purpose of ToH is to move the entire stack to another peg, responding to the following simple rules: a) only one disk should be moved at a time, $b$ ) each move consists of taking the upper disk from one of the stacks and placing it on top of another stack (i.e. a disk can only be moved if it is the uppermost disk on a stack), and c) a larger disk may not be placed over a smaller disk.

\subsubsection{Tetris Game (TG)}

This task is very similar to a puzzle game that requires the solver to strategically rotate, move, and drop a procession of Tetriminos that fall into the rectangular matrix at increasing speeds. Solvers attempt to clear as many lines as possible by completing horizontal rows of blocks without empty space. In the version to use with disabled children, it is possible to adopt a colored wooden tetris composed by a board with raised edges inside which bricks of different shapes and colors must be positioned and fit together, without leaving empty spaces, with the final goal of covering the entire surface.

\subsubsection{Set of Building Blocks (SBB)}

This task consists of a container with 100 plastic pieces divided into five geometric forms (20 blocks for each form with a specific color: yellow hexagon, red pentagon, blue rhombus, orange square, and green triangle) and it can be used to assess the ability to create multiple objects, forms, and ideas starting from unstructured stimuli, combining them as individual preferred. The number of plastic pieces can be changed for increasing or decreasing the complexity of task; the major number of pieces increases the complexity of solution, while the minor number of pieces decreases it. The solver can use these plastic blocks by categorizing them according to different strategies and in a creative way.

For summarizing, the choice of ToH (structured task) can be justified with the presence of a minimum number of moves according to established rules necessary to its solution and only one possible correct solution; also, the main intent of its application is linked to the observation of behaviors adopted by disabled children and adolescents to solve the task and not directly to the analysis of correct responses. The choice of TG (semi-structured task) is due to the presence of different ways (and not only one) used by children and adolescents to occupy the given space; so, the main goal for the use of TG is represented by the observation of behaviors showed by disabled children and adolescents to complete the task rather than by the analysis of type and computation of well-documented correct responses. Finally, the selection of SBB (unstructured task) is completely free from specific rules in its resolution and allows children and adolescents to mentally operate in a more autonomous way compared to previous tasks; for this reason, it can activate divergent and creative thinking in problemsolving strategies.

\subsection{Check-Lists and Procedure}

Two types of check-lists have been created by the first, third, and fifth author to mark the behaviors concerning the general way to solve the tasks (Table 1) and to notice the behaviors about the strategies to solve each specific task (Table 2). In a preliminary phase, the authors carried out audioand video-taped pilot observations of disabled children and adolescents' performance for the three chosen tasks in order to test the goodness and validity of these check-lists. The total time spent for execution of the three tasks was recorded. According to suggestions provided by specialist literature 
and the videotaped observations coded by three independent judges (first, third, and fifth author), it has been possible to modify the following elements:

-the execution time of tasks without the indication of timeout;

-the presentation of tasks with a more clear and intuitive instructions for use with child-friendly words;

-the elimination of redundant behaviors in the same part;

-the difficulty of tasks in relation to the number of disks in the Tower of Hanoi reduced from six to four disks or the number of plastic pieces in the set of Building Blocks.

The final check-lists were revised by the second and fourth author eliminating the ambiguous items and then accepted by all authors. The general checklist contains a list of 20 items (Table 1) for behaviors adaptable to the three tasks with reference to the comprehension of goals and rules of task, manipulative behaviors applied to the whole structure and single disks/bricks/blocks, procedural behaviors to reach the solution of tasks (use of specific strategies; for example, thinking loud), and adaptive behaviors during the explanation by the observer and execution of tasks (e.g., to listen the explanation, to ask for additional information, to search eye contact, and to indicate color and shape of bricks).

Table1. General check-list

\begin{tabular}{|l|}
\hline List of behaviors \\
\hline 1.He/she respects the instructions \\
\hline 2.He/she interrupts the execution of the task \\
\hline 3.He/she understands the goal to be achieved \\
\hline 4.He/she reasons aloud \\
\hline 5.He/she counts the pieces of the object \\
\hline 6.He/she manipulates the single pieces \\
\hline 7.He/she composes and decomposes the whole structure \\
\hline 8.He/she changes strategy when he/she does not reach the expected result \\
\hline 9.He/she realizes that he/she has made a mistake \\
\hline 10.He/she proceeds in a confused and random way \\
\hline 11.He/she asks for further explanations \\
\hline 12.He/she listens to the explanation of the task \\
\hline 13.He/she fixes his/her gaze on the object he/she is manipulating \\
\hline 14.He/she works on the task constantly and without interruption \\
\hline 15.He/she accepts and follows the suggestions \\
\hline 16.He/she seeks eye contact with the observer \\
\hline 17.He/she asks for feedback \\
\hline 18.He/she interrupts the task without completing it \\
\hline 19.He/she indicates color or shape of the pieces \\
\hline 20.During the execution of task he/she is distracted \\
\hline Note - Response format: [ $\sqrt{ }$ ] presence of behavior; [ ] absence of behavior \\
\hline
\end{tabular}

The specific check-list contains three parts, each for single task (see Table 2). For the Tower of Hanoi, it includes four items for behaviors referred to the comprehension of hierarchical structure of task and to specific behaviors such as the reiteration of same movements from a peg to another, the overlapping of disks to understand their size, and so on (e.g. to complete the task even if the disks are overlapped in wrong way). For the Tetris Game, the check-list encloses a total of eighteen items articulated in sub-dimensions to analyze rigidity/flexibility, organizational style, type of errors, and spatial orientation. In detail, it is possible to verify the ability to modify spatial orientation of pieces, modality of task execution according to established schema or flexible format, to observe selfcorrection and self-control ability, and the way in which each piece or brick is rotated inside the wooden board. Lastly, for Building Blocks, the check-list keeps ten items referred to behaviors analyzing operational style, organizational style, and final configuration; specifically, it allows to observe the way in which the building blocks are selected and chosen by children or adolescents (e.g., randomly or in a specific way for the related position), the way in which the building blocks are inserted and allocated in the wooden board (e.g. vertically or horizontally), and the behavior adopted by each child or adolescent to create the final product in convergent or divergent way. 
Table2. Check-list for each task

\begin{tabular}{|c|c|}
\hline \multirow[t]{4}{*}{ TASK 1 (ToH) } & He/she realizes that a disk is bigger than another only after overlapping them \\
\hline & He/she repeats several times the same movement \\
\hline & He/she starts again if the move is wrong \\
\hline & He/she completes the task even if the disks are overlapped in wrong way \\
\hline \multirow{22}{*}{ TASK 2 (TG) } & I - Rigidity / flexibility \\
\hline & He/she puts a brick with the same spatial orientation in the wooden board \\
\hline & He/she maintains the connection between two or more bricks \\
\hline & He/she fits the bricks even if they do not fit correctly in the wooden board \\
\hline & II - Organizational style \\
\hline & He/she organizes the bricks out off the wooden board \\
\hline & $\begin{array}{l}\text { He/she adopts an organized schema or fixed strategy (e.g. e.g., from top to bottom, } \\
\text { from bottom to the top, and from outside to inside, from the right to the left) }\end{array}$ \\
\hline & He/she associates the bricks for color or shape \\
\hline & He/she proceeds in symmetric way \\
\hline & He/she correctly fits one brick at a time in the wooden board \\
\hline & $\mathrm{He} / \mathrm{she}$ realizes joints between the two spaces \\
\hline & III - Type of errors \\
\hline & He/she notes the empty spaces between a brick and another \\
\hline & He/she puts the bricks in a vertical way \\
\hline & He/she verifies the final position of all bricks \\
\hline & $\begin{array}{l}\text { He/she reorganizes the entire board taking into consideration the empty spaces and } \\
\text { adding the missing bricks }\end{array}$ \\
\hline & He/she reorganizes the entire board starting from the first sequence of bricks \\
\hline & He/she corrects the mistakes without the help of observer (or other people) \\
\hline & IV - Spatial orientation (or mental orientation) \\
\hline & $\mathrm{He} / \mathrm{she}$ rotates the bricks inside the wooden board \\
\hline & He/she rotates the bricks only after the established contact with the other bricks \\
\hline & He/she marks the empty space with his/her hands and after inserts the correct bricks \\
\hline \multirow{13}{*}{ TASK 3 (SBB) } & I - Operational style \\
\hline & He/she puts all the blocks in the table and after he/she selects them for color or shape \\
\hline & He/she organizes the blocks in a random way \\
\hline & He/she selects each block at a time from the container \\
\hline & II - Organizational style \\
\hline & $\begin{array}{l}\text { He/she combines geometrical figures using the same color and shape (e.g. all block of } \\
\text { green triangle) }\end{array}$ \\
\hline & He/she creates only geometrical compositions \\
\hline & He/she associates different blocks to create new configurations (e.g. a train) \\
\hline & He/she arranges the blocks vertically in a tridimensional way \\
\hline & III - Final configuration \\
\hline & $\begin{array}{l}\text { He/she produces correspondences between the shape of blocks and their function (e.g., } \\
\text { triangle for the housetop, rhombus for the eyes of puppet) }\end{array}$ \\
\hline & He/she puts together different blocks for the final product \\
\hline & $\begin{array}{l}\text { He/she arranges the blocks dividing them for the same color and shape (e.g. all green } \\
\text { triangles, all red pentagons), not mixing up them }\end{array}$ \\
\hline \multicolumn{2}{|c|}{ Note - Response format: $[\sqrt{ }]$ presence of behavior; $[$ ] absence of behavior } \\
\hline
\end{tabular}

During the observed sessions, participants must be instructed and encouraged by the observer to solve the tasks verbalizing their own thoughts and thinking aloud [32]. As in Short and colleagues' study, learning disabled and developmentally disabled children perform better in verbal and spatial analogies tasks in the "thinking aloud" condition rather than in the "silent" one.

The check-lists allow to record information quickly about how each participant profits in relation to specific problem-solving strategies. Written in a dichotomous format (presence or absence of behavior) and with spaces for brief comments, check-lists are easily usable by educators, teachers for special needs students, or experts in techniques of observation of behaviors. To verify the reliability and validity of direct observations by the two or more independent judges, it is necessary to calculate the inter-observer agreement using the Cohen's Kappa coefficient or Fleiss index. Written permission by parents of observed children or adolescents must be obtained prior to data collection and to start 
the observations. Parents must give their informed consent in accordance with the Code Regulating Personal Data Protection for data privacy.

\section{DisCUSSION AND CONCLUSIONS}

This paper is likely to provide a contribution to fill the lack of suggestions in reference to this aspect of assessment of abilities in disabled students. We believe that it is useful formulate an idea of project work focused on the analysis of problem-solving strategies, starting from the choice of tasks adequate and similar for definition to those used in this observational study, and concluding with the comparison between performances of typically developed students and those of disabled ones. So, in the hypothetical and longitudinal project work, it could be very important to carry out the qualitative assessment of problem-solving abilities, using the abovementioned check-lists both in pre- and posttraining for evaluating the enhancement of these abilities in disabled students after realizing educational and process-based trainings focused on the exercise of executive functions $[33,34]$. The comparison between the check-list filled in pre-training and that in post-training can be useful to highlight the most deficient areas of problem-solving, the areas where improvements have been recorded following a specific intervention, and the areas where improvements have not be realized.

This modus operandi could have an effect on school achievement also in children without disability $[35,36]$. As reported by Thorell et al. [35], preschool children receiving computerized training of visuo- spatial working memory and inhibition for five weeks improved significantly on trained tasks respect to control groups. Holmes et al. [36] found that the majority of children with low working memory skills, assessed on measures of working memory, IQ and academic attainment before and after training on either adaptive or non- adaptive programs, showed substantial and sustained improvements in working memory linked to reading and mathematical abilities with adaptive trainings.

The effectiveness of cognitive training has been also confirmed in children with ADHD: in Klingberg, Fernell, Olesen, Johnson et al.' study [37], it emerged that 7 to 12-years-old children with ADHD trained with computerized programs for over 20 days reached good performance in span and visuospatial working memory in post-training and follow up at three months and improved inhibition and reasoning abilities. Similar results were obtained by Holmes, Gathercole, Place, Dunning, et al. [38], indicating that 8 to 11-years-old children with ADHD and children with deficient working memory, trained with cognitive and pharmacological programs for 20 days, obtained good performance in verbal and visuo-spatial working memory using cognitive training. In addition, Söderqvist, Bergman Nutley, Ottersen et al. [39] tested the efficacy of computerized training for five weeks on working memory and non-verbal reasoning in two groups of 8 to 11-years-old children with intellectual disability (IQ < 70): experimental group of children significantly enhanced performance in non-verbal reasoning and working memory tasks compared to control group.

To improve the sustained attention and shifting in disabled children and adolescents it could be adequate the usage of "barrage activities" (target: colors, letters, numbers, or figures) in presence of distractors stimuli for increasing the concentration on the given task $[40,41]$ or the "organization of points" according to the Feuerstein et al.'s method [42] for the building of geometrical shapes alike to given model combining the points in a datasheet. To increase the working memory, the number span (e.g. remember list of numbers), word span (e.g. remember list of words), and alpha span tasks (e.g. remember list of words in different types of presentation) could be used [43, 44]. Proficiently, the Tower of Hanoi and the Tangrams for Kids could be adopted with disabled children in order to enhance their planning and problem-solving abilities. In detail, the tangram is a two-dimensional rearrangement puzzle created by cutting a square into seven geometric shapes named "tans" [45]; each tangram puzzle contains two large right triangles, one medium-sized right triangle, two small right triangles, one parallelogram, and one small square, and, arranged correctly, these pieces can be fitted together as a large square, rectangle, or triangle or in a creative way. Solving tangram puzzles appears to activate parts of the brain associated with creative thinking and trial-and-error problem-solving [46].

The application of check-lists for observing the behavioral patterns of disabled children and adolescents in the execution of the abovementioned tasks requires a good level of expertise in the observational methods, in direct or indirect form. Some suggestions in this contribution could be provided to overcome limits in this qualitative approach. Firstly, the choice of different types of 
participants will allow us to extend the analysis to the other cases and the inclusion of control group will permit us to understand if the strategies adopted in the solution of these tasks are peculiar to this population or similarly present also in individuals with typical functioning. Furthermore, the three tasks (ToH, TG, and SBB) will be applied without reference to standardized and quantitative scores but rather to qualitative analyses, observing the type of solutions adopted by participants for the tasks and the adequate or inadequate strategies of problem-solving employed by participants in each task. We think that the application of this type of observation with the use of check-lists could be useful to create a linkage between qualitative and quantitative research to enhance the knowledge of the problem-solving strategies in atypical developed children.

Future research with the application of these check-lists could be carried out with children with DS and WS to deep the knowledge of problem-solving strategies in atypically developed target.

\section{REFERENCES}

[1] Sternberg, R.J., Jarvin, L., and Grigorenko, E.L. (2009). Teaching for wisdom, intelligence, creativity, and success. Corwin Press: SAGE Publications Ltd.

[2] Denckla, M.B. (1994). Measurement of executive function. In G. R. Lyon (Ed.), Frames of reference for the assessment of learning disabilities: New views on measurement issues (pp.117-142), Paul H Brookes Publishing Co.

[3] Diamond, A. (2013). Executive functions. Annual Review of Psychology, 64, 135-168.

[4] Miyake, A., Friedman, N. P., Emerson, M. J., Witzki, A. H., Howerter A., and Wager, T. D. (2000). The unity and diversity of executive functions and their contributions to complex "frontal lobe" tasks: a latent variable analysis. Cognitive Psychology, 41, 49-100.

[5] Miyake, A., and Friedman, N. P. (2012). The nature and organization of individual differences in executive functions: four general conclusions. Current Directions in Psychological Sciences, 21, 8-14.

[6] Heaton, S. K., Chelune, G. J., Talley, J. L., Kay, G. G., and Curtiss, G. (1993). Wisconsin Card Sorting Test Manual: Revised and expanded. Odessa, FL: Psychological Assessment Resources, Inc.

[7] Anderson, P., Anderson, V., and Lajoie, G. (1996). The tower of London test: Validation and standardization for pediatric populations. The Clinical Neuropsychologist, 10(1), 54-65.

[8] Costanzo, F., Varuzza, C., Menghini, D., Addona, F., Gianesini, T. and Vicari, S. (2013). Executive functions in intellectual disabilities: a comparison between Williams syndrome and Down syndrome. Research in Developmental Disabilities, 34, 1770-1780.

[9] Zelazo, P. D. (2006). The Dimensional Change Card Sort (DCCS): a method of assessing executive function in children. Nature Protocol, 1, 297-301.

[10] Danielsson, H., Henry, L., Rönnberg, J., and Nilsson, L. G. (2010). Executive functions in individuals with intellectual disability. Research in Developmental Disabilities, 31(6), 1299-1304.

[11] Krikorian, R., Bartok, J., and Gay, N. (1994). Tower of London procedure: a standard method and developmental data. Journal of Clinical and Experimental Neuropsychology, 16(6), 840-850.

[12] Lanfranchi, S., Jerman, O., Dal Pont, E., Alberti A. and Vianello, R. (2010). Executive function in adolescents with Down syndrome. Journal of Intellectual Disability Research, 54, 308-319.

[13] Carney, D. P. J., Brown, J. H. and Henry, L. A. (2013). Executive function in Williams and Down syndromes. Research in Developmental Disabilities, 34, 46-55.

[14] Meltzer, L., and Krishnan, K. (2007). Executive Function Difficulties and Learning Disabilities: Understandings and Misunderstandings. In L. Meltzer (Ed.), Executive function in education: From theory to practice (pp. 77-105). Guilford Press.

[15] Mammarella, I. C., Cardillo, R., and Zoccante, L. (2019). Differences in visuospatial processing in individuals with nonverbal learning disability or autism spectrum disorder without intellectual disability. Neuropsychology, 33(1), 123.

[16] Atkinson, B. R., and Seunath, O. H. (1973). The effect of stimulus change on attending behavior in normal children and children with learning disorders. Journal of Learning Disabilities, 6(9), 569-573.

[17] Tarver, S. G., Hallahan, D. P., Kauffman, J. M., and Ball, D. W. (1976). Verbal rehearsal and selective attention in children with learning disabilities: A developmental lag. Journal of Experimental Child Psychology, 22(3), 375-385.

[18] Havertape, J. F., and Kass, C. E. (1978). Examination of problem solving in learning disabled adolescents through verbalized self-instructions. Learning Disability Quarterly, 1(4), 94-100.

[19] Lucangeli, D., Fastame, M. C., Pedron, M., Porru, A., Duca, V., Hitchcott, P. K., and Penna, M. P. (2019). Metacognition and errors: the impact of self-regulatory trainings in children with specific learning disabilities. ZDM, 51(4), 577-585. 
[20] Shafrir, U., Siegel, L. S., and Chee, M. N. (1990). Learning disability, inferential skills, and post failure reflectivity. Journal of Learning Disabilities, 23(8), 506-514.

[21] Swanson, H. L. (1993). An information processing analysis of learning disabled children's problem solving. American Educational Research Journal, 30(4), 861-893.

[22] Zelazo, P. D., Burack, J. A., Benedetto, E., and Frye, D. (1996). Theory of mind and rule use in individuals with Down's syndrome: a test of the uniqueness and specificity claims. The Journal of Child Psychology and Psychiatry, 37, 479-484.

[23] Lanfranchi, S., Cornoldi, C., and Vianello, R. (2004). Verbal and visuo-spatial working memory deficits in children with Down syndrome. American Journal on Mental Retardation, 109(6), 456-466.

[24] Meneghetti, C., Toffalini, E., Carretti, B., and Lanfranchi, S. (2018). Mental rotation ability and everydaylife spatial activities in individual with Down syndrome. Research in Developmental Disabilities, 72, 33-41.

[25] Frick, A., Hansen, M. A., and Newcombe, N. S. (2013). Development of mental rotation in 3- to 5-yearold children. Cognitive Development, 28, 386-399.

[26] Russell, J., Jarrold, C., and Henry, L. (1996). Working memory in children with autism and with moderate learning difficulties. Child Psychology and Psychiatry and Allied Disciplines, 37(6), 673-686.

[27] Baddeley, A. (1986). Working memory. Oxford: Clarendon Press.

[28] Lanfranchi, S., Jerman, O., and Vianello, R. (2009). Working memory and cognitive skills in individuals with Down syndrome. Journal of Child Neuropsychology, 15, 397-416.

[29] Camp, J.S., Karmiloff-Smith, A., Thomas, M.S.C., and Farran, E.K. (2016). Cross-syndrome comparison of real-world executive functioning and problem-solving using a new problem-solving questionnaire. Research in Developmental Disabilities, 59, 80-92.

[30] Yoder, P., and Symons, F. (2010). Observational measurement of behavior. New York: Springer Publishing Company.

[31] Suen, H. K., and Ary, D. (2014). Analyzing quantitative behavioral observation data. New York: Psychology Press.

[32] Short, E. J., Schatschneider, C., Cuddy, C. L., Evans, S. W., Dellick, D. M., and Basili, L. A. (1991). The effect of thinking aloud on the problem-solving performance of bright, average, learning disabled, and developmentally handicapped students. Contemporary Educational Psychology, 16(2), 139-153.

[33] Titz, C., and Karbach, J. (2014). Working memory and executive functions: effects of training on academic achievement. Psychological Research, 78, 852-868.

[34] Gupta, S. K., and Venkatesan, S. (2014). Reappraisal of research on executive function training in children with learning disabilities. International Journal of Psychology and Psychiatry, 2(1), 7-18.

[35] Thorell, L. B., Lindqvist, S., Bergman Nutley, S., Bohlin, G., and Klingberg, T. (2009). Training and transfer effects of executive functions in preschool children. Developmental Science, 12(1), 106-113.

[36] Holmes, J., Gathercole, S. E., and Dunning, D. L. (2009). Adaptive training leads to sustained enhancement of poor working memory in children. Developmental Science, 12(4), 9-15.

[37] Klingberg, T., Fernell, E., Olesen, P. J., Johnson, M., Gustafsson, P., Dahlström, K., Christopher, G., Gillberg, M. D., Hans Forssberg, and Westerberg, H. (2005). Computerized training of working memory in children with ADHD-a randomized, controlled trial. Journal of the American Academy of Child and Adolescent Psychiatry, 44(2), 177-186.

[38] Holmes, J., Gathercole, S. E., Place, M., Dunning, D. L., Hilton, K. A., and Elliott, J. G. (2010). Working memory deficits can be overcome: Impacts of training and medication on working memory in children with ADHD. Applied Cognitive Psychology, 24(6), 827-836.

[39] Söderqvist, S., Bergman Nutley, S., Ottersen, J., Grill, K. M., and Klingberg, T. (2012). Computerized training of non-verbal reasoning and working memory in children with intellectual disability. Frontiers in Human Neuroscience, 6, 271, 1-8.

[40] Di Nuovo, S. (2000). Attenzione e concentrazione. 7 test e 12 training di potenziamento. Trento, Italy: Erickson.

[41] Marzocchi, G., Portolan, S., and Usilla, A. (2016). Autoregolare l'attenzione. Attività su vigilanza, inibizione, memoria di lavoro, controllo interferenza e flessibilità cognitiva. Trento, Italy: Erickson.

[42] Feuerstein, R., and Jensen, M. R. (1980). Instrumental enrichment: Theoretical basis, goals, and instruments. The Educational Forum, 44(4), 401-423.

[43] Andrich, S., and Miato, L. (2006). Memoria visiva. Trento, Italy: Erickson.

[44] Rudland, J. (2008). Potenziare la memoria a breve termine. Trento, Italy: Erickson.

[45] Slocum, J., Botermans, J., Gebhardt, D., Raizer, H., Sonnevald, D., and Van Splunteren, C. (2003). Tangrams: The world's first puzzle craze. Sterling: New York. 
[46] Hu, Z., Lam, K.F., and Yuan, Z. (2019). Effective Connectivity of the Fronto-Parietal Network during the Tangram Task in a Natural Environment. Neuroscience, 422, 202-211.

\section{AUTHORS' BIOGRAPHY}

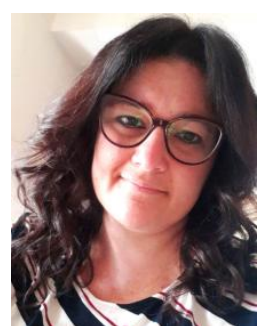

Elisabetta Sagone, is $\mathrm{PhD}$ in Methods of Educational Processes and Senior research in Developmental and Educational Psychology at Department of Educational Sciences, University of Catania, Italy. She is Reviewer for Health Psychology, Journal of Cognitive Education and Psychology, BMC Public Health, BMC Research Notes, Frontiers in Psychology and Education and Member of Editorial Board of INFAD. She works as teacher for Training Courses in Teaching for Special Needs and Disabled Children at Department of Educational Sciences, University of Catania; in addition, she is interested in scholastic and psychology and techniques of behavioral infant observation. Her research topics concern resilience, psychological well-being and self-efficacy in life skills in developmental age, divergent thinking in typical and atypically developed children, coping in parents of disabled children, parenting in life span, and burnout in teachers. She is author of several publications indexed in Scopus and ISI Web of Sciences.

Maria Elvira De Caroli, is Full Professor of Developmental and Educational Psychology; her mains areas of research are focused on divergent thinking and metaphorical creativity in typically and atypically developed subjects, ethnic prejudice and stereotypical attitudes, and representations of Parental Self, motherhood, and fatherhood in life span.

Maria Luisa Indiana, is Ph.D. in Psychology and her scientific interests of research are focused on positive psychology, resilience, well-being of typically and atypically developed children and adolescents, coping strategies, and perceived self-efficacy in life skills in developmental age. Rossella Falanga, is Ph.D. in Educational Sciences and her scientific interests are divergent abilities in life span and metaphorical creativity, values, ethnic prejudice and stereotypical attitudes, prosocialmoral development, and hope.

Erica Napoli, is Ph.D. in Psychology; her scientific interests are focused on observation of development of disabled people.

Citation: Elisabetta Sagone, et.al. "Observing Problem-Solving Strategies in Disabled Children and Adolescents with the Use of Check-Lists" International Journal of Humanities Social Sciences and Education (IJHSSE), vol 7, no. 6, 2020, pp. 187-195. doi: http://dx.doi.org/10.20431/2349-0381.0706020.

Copyright: (C) 2020 Authors. This is an open-access article distributed under the terms of the Creative Commons Attribution License, which permits unrestricted use, distribution, and reproduction in any medium, provided the original author and source are credited. 